\title{
Effect of Oral Care Gel for Burning Mouth Syndrome in a Patient with Hepatitis C: A Case Report
}

\author{
Yumiko Nagao ${ }^{a}$ Yuji Kawahigashi ${ }^{a}$ Kanae Kimura ${ }^{a}$ Michio Sata ${ }^{b, c}$ \\ ${ }^{a}$ Department of Organ System Interactions and Information, Faculty of Medicine, Saga \\ University, Saga, Japan; ${ }^{b}$ Nishinihon Hospital, Kumamoto, Japan; ${ }^{C}$ Research Center for \\ Innovative Cancer Therapy, Kurume University School of Medicine, Kurume, Japan
}

\section{Keywords}

Burning mouth syndrome $\cdot$ Hepatitis $C$ virus $\cdot$ Oral care gel

\begin{abstract}
Burning mouth syndrome (BMS) is a burning sensation in the mouth with no underlying dental or medical cause. To date, there is no satisfactory treatment for BMS. Herein, we present the case of a 42-year-old female presenting with hepatitis $C$ virus infection along with BMS. Despite two interferon therapies and a sustained virologic response, the discomfort in her oral mucosa persisted. At the age of 51 , the patient complained of burning sensation and tingling pain in the tongue; a thin layer of REFRECARE- $\mathrm{H}^{\circledR}$, an oral care gel (therapeutic dentifrice), was applied on the oral membrane after each meal for 60 days. Application of REFRECARE- $\mathrm{H}^{\circledR}$ decreased the various symptoms including tingling pain, oral discomfort, breath odor, sleep disorder, depressive mood, and jitteriness. The improvement in quality of life continued for 30 days after application of the gel. These findings indicate that REFRECARE- $\mathrm{H}^{\circledR}$ may be effective in reducing the symptoms associated with BMS. Long-term follow-up studies with larger number of patients are required to elucidate the therapeutic effects of this gel.




\section{Case Reports in Gastroenterology}

\section{Introduction}

Burning mouth syndrome (BMS) is a chronic pain disorder characterized by burning and stinging of the oral cavity in the absence of any organic disease. BMS typically affects middle-aged women [1]. A highly characteristic feature of this disease is the presence of a completely normal-appearing oral mucosa in association with the complaint of an intensely burning mouth or tongue. The tissue has the same color as that of the surrounding tissue, with normal distribution of tongue papillae. So far, there is no satisfactory treatment for BMS. Hormonal changes, neurologic problems, and idiopathic disease are as difficult to identify as they are to treat.

The number of hepatitis $\mathrm{C}$ virus (HCV) carriers in Japan is estimated to be 1.5-2 million. $\mathrm{HCV}$ infection is the leading cause of liver cirrhosis and cancer, and also induces extrahepatic manifestations such as lichen planus [2, 3]. We previously reported the visual analog scale (VAS) and effects of REFRECARE-H ${ }^{\circledR}$ (EN Otsuka Pharmaceutical Co., Ltd.), a hinokitiolcontaining oral care gel, on patients with oral lichen planus associated with HCV infection [4]. REFRECARE- $\mathrm{H}^{\circledR}$ is a therapeutic dentifrice containing hinokitiol, which can remove dental stains and general oral debris, and is effective in the prevention of breath odor and gum diseases.

HCV also presents with a psychiatric challenge. Patients with HCV are more likely to have psychiatric disorders, with depression being the most frequent and clinically important [5]. Herein, we report the case of a 42-year-old woman with HCV infection, who was diagnosed with BMS and, subsequently, treated with REFRECARE-H ${ }^{\circledR}$. VAS is a simple and frequently used method for evaluating variations in pain intensity [6]. Therefore, we investigated the VAS and effects of REFRECARE- $\mathrm{H}^{\circledR}$ on this patient.

\section{Case Presentation}

In July 2008, a 42-year-old Japanese female visited the Kurume University Hospital (Fukuoka, Japan) complaining of glossal discomfort before interferon treatment for chronic hepatitis C. She was diagnosed with BMS by a specialist oral surgeon. No signs or symptoms of oral lichen planus, Sjögren's syndrome, Candida albicans, and oral cancer were observed in the patient's oral cavity. There was no history of blood transfusion, tattoo, or injection drug use. Moreover, the patient was not a habitual alcohol drinker or smoker. Subsequently, she received Peg-interferon alpha- $2 \mathrm{~b}$ and ribavirin therapy for chronic hepatitis $\mathrm{C}$ for 48 weeks, but did not reach sustained virologic response. At the age of 44 (in 2010), the patient received direct-acting antivirals, daclatasvir (NS5A inhibitor) plus Peg-interferon alpha-2a and ribavirin for 24 weeks. Eventually, the eradication of HCV was successful in the patient. However, after achieving a sustained virologic response following the treatment, the discomfort in the oral mucosa did not disappear completely.

At the age of 51 (in 2016), she consulted with the same oral surgeon about the intraoral discomfort, but no organic abnormality was found in the mouth. In February 2017 (age 51), she visited the oral surgeon again with a complaint of burning sensation and tingling pain in the tongue. She did not experience any taste disorder. Alternatively, she was under medica- 


\section{Case Reports in Gastroenterology}

Nagao et al.: Effect of Oral Care Gel for Burning Mouth Syndrome in a Patient with Hepatitis C: A Case Report

tion (etizolam and Chinese medicine) for symptoms related to menopause; however, the intraoral symptoms were not relieved.

REFRECARE- $\mathrm{H}^{\circledR}$, an oral care gel, was applied as a thin layer on the oral membrane after each meal for 60 days. A VAS is a horizontal line, $100 \mathrm{~mm}$ in length, anchored by word descriptors at each end, as illustrated in Figure 1. The patients marked on the line the point that they felt represented their perception of their current state, such as tingling pain of the tongue during rest, oral discomfort, breath odor, dry mouth, oral pain at mealtimes, sleep disorder, depressive mood, and jitteriness. The VAS score was determined by measuring, in millimeters, from the left hand end of the line to the point marked by the patient.

The patient checked the VAS every day form February 2, 2017 to April 30, 2017, before application of REFRECARE- ${ }^{\circledR}, 2$ months during application of the gel, and 1 month after the end of application (REFRECARE- ${ }^{\circledR}$ free). Mean values and changes of VAS are shown in Table 1 and Figure 2, respectively. Application of REFRECARE- $\mathrm{H}^{\circledR}$ improved the quality of life such as tingling pain, oral discomfort, breath odor, sleep disorder, depressive mood, and jitteriness; the improvement in symptoms continued for 30 days after application of REFRECARE- $\mathrm{H}^{\circledR}$. Hence, we believe that REFRECARE- $\mathrm{H}^{\circledR}$ could be effective in reducing the symptoms associated with BMS.

\section{Discussion}

The prevalence of BMS is thought to range from 0.7 to 15\% [7-9]. It affects middle-aged and older women (mean age, 50-60 years), with a female-to-male ratio varying from 3:1 to $16: 1[10,11]$.

The etiology of BMS is varied, making it difficult to decipher the disease clinically [1]. The symptoms of pain appear to be due to various reasons such as microorganisms (especially Candida albicans), xerostomia with Sjögren's syndrome, nutritional deficiencies, anemia, hormone imbalance, neuropsychiatric abnormalities, diabetes mellitus, mechanical trauma, and idiopathic causes.

The present case was complicated as the patient presented with hepatitis $\mathrm{C}$ at the onset of BMS. Patients with hepatitis $\mathrm{C}$ have high rates of psychological symptoms and reduced quality of life when compared with the general population $[12,13]$. The prevalence of depression with HCV infection is reported to be $24-28 \%$ [5]. In this report, the reason for the onset of BMS is unknown, but HCV infection may have acted as a trigger for the development of BMS.

Antidepressant therapy plays a major role in the management of BMS once other precipitating factors have been excluded [1]. Tricyclic antidepressants or a selective serotonin reuptake inhibitor may be used $[14,15]$. In addition, recent reports have suggested the role of daily low-dose benzodiazepines such as clonazepam [16].

Subclinical Candida infection has been suggested as one of the etiological factors in patients with BMS [17]. REFRECARE- ${ }^{\circledR}$, a gel with efficacy against Candida albicans, might aid in minimizing the tingling pain and oral discomfort, thereby improving the quality of life of the patient in this case report.

We have previously demonstrated that REFRECARE- $\mathrm{H}^{\circledR}$ was instrumental in decreasing the subjective symptoms in patients with oral lichen planus [4]. In the present study, appli- 
Nagao et al.: Effect of Oral Care Gel for Burning Mouth Syndrome in a Patient with Hepatitis C: A Case Report

cation of REFRECARE- $\mathrm{H}^{\circledR}$ improved the quality of life of the patient in terms of dry mouth, breath odor, oral freshness, oral pain during rest, oral pain at mealtimes, taste disorder, loss of appetite, sleep disorder, depressive mood, and jitteriness.

In conclusion, this report demonstrates that oral care gel can be used to address the subjective symptoms and improve the quality of life of a patient with BMS.

\section{Acknowledgements}

This study was supported in part by a Grant-in-Aid for Scientific Research (C) (17K12012) from the Ministry of Education, Culture, Sports, Science and Technology of Japan.

\section{Statement of Ethics}

The authors have no ethical conflicts to disclose. Informed consent was obtained from the patient before inclusion in this report.

\section{Disclosure Statement}

Yumiko Nagao, Yuji Kawahigashi, and Kanae Kimura belong to a department funded by Nishinihon hospital. Michio Sata declares no conflicts of interest.

\section{References}

1 Regezi JA, Sciubba JJ, Jordan RCK: Burning mouth syndrome; in: Oral Pathology: Clinical Pathologic Correlations. 7th edition. Philadelphia, Elsevier, 2016, pp 127-128.

-2 Gumber SC, Chopra S: Hepatitis C: a multifaceted disease. Review of extrahepatic manifestations. Ann Intern Med 1995;123:615-620.

3 Nagao Y, Sata M: Hepatitis C virus and lichen planus. J Gastroenterol Hepatol 2004;19:1101-1113.

4 Nagao Y, Sata M: Effect of oral care gel on the quality of life for oral lichen planus in patients with chronic HCV infection. Virol J 2011;8:348.

5 Golden J, O’Dwyer AM, Conroy RM: Depression and anxiety in patients with hepatitis C: prevalence, detection rates and risk factors. Gen Hosp Psychiatry 2005;27:431-438.

6 Chapman CR, Casey KL, Dubner R, Foley KM, Gracely RH, Reading AE: Pain measurement: an overview. Pain 1985;22:1-31.

7 Lipton JA, Ship JA, Larach-Robinson D: Estimated prevalence and distribution of reported orofacial pain in the United States. J Am Dent Assoc 1993;124:115-121.

8 Riley JL 3rd, Gilbert GH, Heft MW: Orofacial pain symptom prevalence: selective sex differences in the elderly? Pain 1998;76:97-104.

9 Tammiala-Salonen T, Hiidenkari T, Parvinen T: Burning mouth in a Finnish adult population. Community Dent Oral Epidemiol 1993;21:67-71.

10 Bergdahl M, Bergdahl J. Burning mouth syndrome: prevalence and associated factors. J Oral Pathol Med 1999;28:350-354.

11 Scala A, Checchi L, Montevecchi M, Marini I, Giamberardino MA: Update on burning mouth syndrome: overview and patient management. Crit Rev Oral Biol Med 2003;14:275-291. 
Nagao et al.: Effect of Oral Care Gel for Burning Mouth Syndrome in a Patient with Hepatitis C: A Case Report

12 Rodger AJ, Jolley D, Thompson SC, Lanigan A, Crofts N: The impact of diagnosis of hepatitis C virus on quality of life. Hepatology 1999;30:1299-1301.

-13 Cordoba J, Flavia M, Jacas C, Sauleda S, Esteban JI, Vargas V, Esteban R, et al: Quality of life and cognitive function in hepatitis C at different stages of liver disease. J Hepatol 2003;39:231-238.

14 Lopez-Jornet P, Camacho-Alonso F, Leon-Espinosa S: Efficacy of alpha lipoic acid in burning mouth syndrome: a randomized, placebo-treatment study. J Oral Rehabil 2009;36:52-57.

-15 Yamazaki Y, Hata H, Kitamori S, Onodera M, Kitagawa Y: An open-label, noncomparative, dose escalation pilot study of the effect of paroxetine in treatment of burning mouth syndrome. Oral Surg Oral Med Oral Pathol Oral Radiol Endod 2009;107:e6-e11.

16 Arduino PG, Cafaro A, Garrone M, Gambino A, Cabras M, Romagnoli E, Broccoletti R: A randomized pilot study to assess the safety and the value of low-level laser therapy versus clonazepam in patients with burning mouth syndrome. Lasers Med Sci 2016;31:811-816.

17 Chen Q, Samaranayake LP: Growth of the fungal pathogen Candida in parotid saliva of patients with burning mouth syndrome. Microbios 2000;102:45-52. 
Nagao et al.: Effect of Oral Care Gel for Burning Mouth Syndrome in a Patient with

Q1 Tingling pain of the tongue during rest

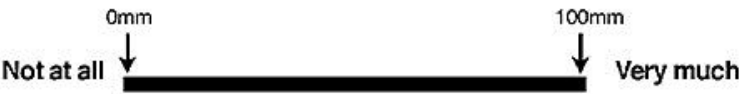

Q2 Oral discomfort

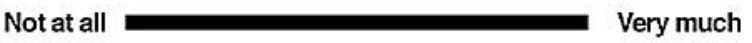

Q3 Breath odor

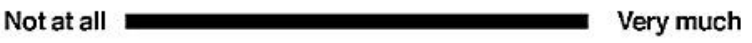

Q4 Dry mouth

Not at all

Very much

Q5 Oral pain at a mealtimes

Not at all

Very much

Q6 Sleep disorder

Not at all

Very much

Q7 Depressive mood

Not at all Very much

Q8 Jitteriness

Not at all

Very much

Fig. 1. Visual analog scale (VAS) of 8 items. A VAS is a horizontal line, $100 \mathrm{~mm}$ in length, anchored by word descriptors at each end. 
Nagao et al.: Effect of Oral Care Gel for Burning Mouth Syndrome in a Patient with Hepatitis C: A Case Report

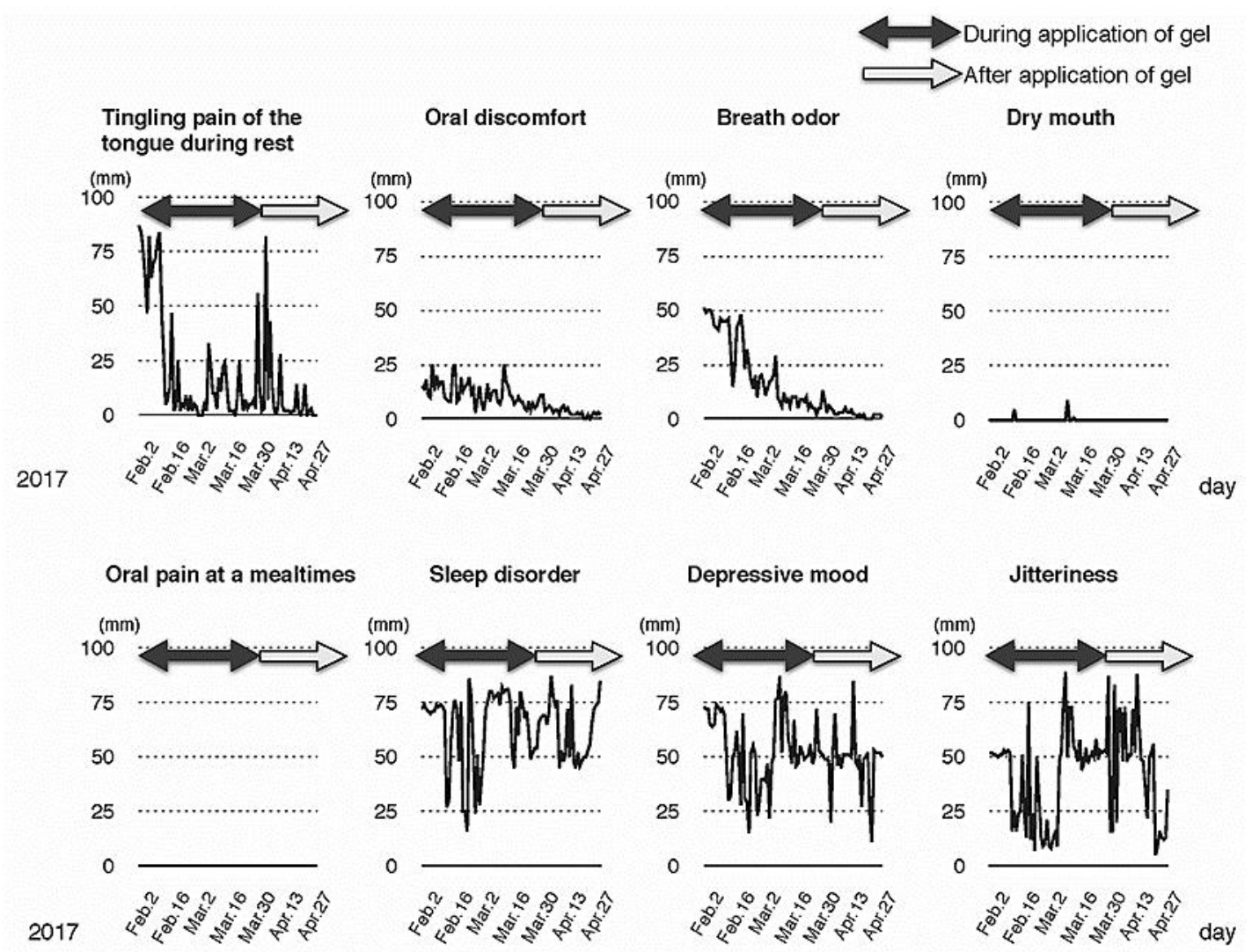

Fig. 2. The distributions of visual analog scale score before, during, and after the application of REFRECARE-H ${ }^{\circledR}$. All subjective symptoms decreased during and after the application. 
Table 1. Visual analog scale scores before, during, and after the application of REFRECARE-H ${ }^{\circledR}$

\begin{tabular}{lcll}
\hline Subjective symptoms & $\begin{array}{l}\text { Before application } \\
\text { (Feb. 2, 2017), mm }\end{array}$ & $\begin{array}{l}\text { During application } \\
\text { (from Feb. 3 to Mar. 31, 2017) } \\
\text { (mean } \pm \text { SD), mm }\end{array}$ & $\begin{array}{l}\text { After application } \\
\text { (from Apr. 1 to Apr. 30, 2017) } \\
\text { (mean } \pm \text { SD), mm }\end{array}$ \\
\hline $\begin{array}{l}\text { Tingling pain in the } \\
\quad \text { tongue during rest }\end{array}$ & 87 & & \\
Oral discomfort & 15 & $20.98 \pm 26.46$ & $10.20 \pm 18.77$ \\
Breath odor & 51 & $11.75 \pm 5.49$ & $3.53 \pm 2.58$ \\
Dry mouth & 0 & $22.16 \pm 16.01$ & $2.87 \pm 2.64$ \\
Oral pain at mealtimes & 0 & $0.26 \pm 1.36$ & 0 \\
Sleep disorder & 72 & 0 & 0 \\
Depressive mood & 73 & $63.18 \pm 18.00$ & $62.63 \pm 13.40$ \\
Jitteriness & 52 & $53.47 \pm 16.31$ & $47.97 \pm 13.37$ \\
\hline
\end{tabular}

Nagao et al.: Effect of Oral Care Gel for Burning Mouth Syndrome in a Patient with Hepatitis C: A Case Report 